\title{
A cost effective computational design of maximum power point tracking for photo-voltaic cell
}

\author{
Yoganandini A. P. ${ }^{1}$, Anitha G. S. ${ }^{2}$ \\ ${ }^{1}$ Department of E\&C, Sambharam Institute of Technology, Bengaluru, India \\ ${ }^{2}$ Department of Electronical \& Electronics RVCE, Bengaluru, India
}

\section{Article Info \\ Article history: \\ Received Apr 18, 2018 \\ Revised Sep 14, 2018 \\ Accepted Oct 8, 2018}

\section{Keywords:}

Battery

Energy efficiency

MPPT

Photo-voltaic

Solar energy

\begin{abstract}
Maximum Power Point Tracking (MPPT) is one of the essential controller operations of any Photo-Voltaic (PV) cell design. Developing an efficient MPPT system includes a significant challenge as there are various forms of uncertainty factors that results in higher degree of fluctuation in current and voltage in PV cell. After reviewing existing system, it has been found that there is no presence of any benchmarked model to ensure a better form of computational model. Hence, this paper presents a novel and very simple design of MPPT without using any form of complex design mechanism nor including any form of frequently used iterative approach. The proposed model is completely focused on developing an algorithm that takes the input of voltage (open circuit), current (short circuit), and max power in order to obtain the peak power to be extracted from the PV cells. The study outcome shows faster response time and better form of analysis of current-voltagepower for given state of PV cells.
\end{abstract}

Copyright () 2019 Institute of Advanced Engineering and Science. All rights reserved.

\section{Corresponding Author:}

Yoganandini A. P.,

Department of E\&C,

Sambharam Institute of Technology,

Bengaluru, India.

Email: yoganandinipari@gmail.com

\section{INTRODUCTION}

Maximum Power Point Tracking (MPPT) is considered as a process that is responsible for obtaining information about the highest usage of power in a controller design [1], [2]. However, it is strongly correlated with Photo-Voltaic (PV) module system subjected to specific set of environmental and operating conditions. In this mechanism, the contribution of both current and voltage is highly essential in order to generate highest power that is also represented as peak point of power [3], [4]. However, generally there is higher degree of stability problems associated the power in PV cells as solar radiation fluctuates very often and is highly dependent on various external parameters e.g. temperature of solar cell [5]. The core role of MPPT approach is to make the PV cell work under the significant scale of voltage that corresponds to the highest degree of power point [6]. This operation basically assists in extracting highest level of residual power right from the PV cells. The easiest way to understand the operational flow of MPPT is -1) compute the output of PV cell, 2) perform and analysis with the voltage associated with batter, 3) determine the optimal power that is capable of generating power by PV cell for the purpose of battery charging, 4) perform conversion to the optimal voltage in order to obtain the highest amount of current that are drawn to the battery unit [7]. This process can also act as a source of origination of energy supply for DC loads. It has been found that climatic condition and highly discharged battery state are the adverse condition that negatively affects MPPT. An efficient design of the controller can be achieved using MPPT that are characterized by following: i) controller system for MPPT assists in rectifying the fluctuation occurred in voltage and current occurring in solar cells especially, ii) it can perform extraction of the highest level of power in order to ensure better 
operation of voltage required for efficient DC-DC controller system, iii) it permits the user to make use of PV cells associated with maximum output voltage as compared to the voltage required for operating the battery unit, iv) it is also claimed to minimize the complexity associated with the system that normally surfaces during higher peak loads. v) it also allows to be used for multiple number of sources of energy as efficient controlling of DC-DC converter can be carried out more efficiently, vi) the applicability of the MPPT controller system is more towards renewable resources [8]-[10]. An effective design of MPPT controller system has many clauses to be checked for as i) computing the normal voltage of battery that is required for charging the controller and likewise perform selection of such voltage, ii) selection of appropriate current for charging, iii) ensure that the highest charging current is under the limits of standards imposed on operating PV cells, etc. Existing system shows that there are various forms of classification of controller design strategy e.g. i) incremental conductance, ii) perturb and observe, iii) constant voltage, iv) current sweep. At present, there is various research works being carried out towards developing MPPT for designing an efficient controller system [11]. Inspite of associated benefits of existing approaches, there are nonavailability of any form of benchmarked models to ensure the best performance of MPPT. This leads to motivate that there is an immense need to perform a dedicate research work toward developing an efficient MPPT-based model for developing an efficient controller system applicable in real-life conditions. Therefore, the contribution of the proposed system is to introduce one such simplistic computational model to address such problems. The proposed model emphasizes on offering a cost effective computational model that can perform a precise identification of MPPT state considering PV cells under variable conditions ofdifferent constraints. Section 1.1 discusses about the existing literatures where different techniques are discussed for detection schemes used in MPPT scheme followed by discussion of research problems in Section 1.2 and proposed solution in 1.3. Section 2 discusses about algorithm implementation followed by discussion of result analysis in Section 3. Finally, the conclusive remarks are provided in Section 4.

\subsection{Background}

This section is a continuation of our prior exploration towards effective MPPT techniques where further updated information is added on the top of it [12]. Existing literatures have been recorded to find the importance of accuracy towards MPPT as reported by the work of Ahmed and Salam [13]. Study of MPPT has also been carried out towards designing inverter for enhancing current quality. This fact was discussed by Azari et al. [14]; however, the study lacks efficiency in inverter design. Caporal et al. [15] have presented a study where enhanced PV system has been developed to offer better predictive scheme. Adoption of approximation theory has been seen in the work of Ghasemi et al. [16] with more focus on speed of obtaining MPPT considering partial shaded condition. Similar approach of modeling was also seen in the work of Jeyaprabha and Selvakumar [17] where flyback converter is utilized. Jiang et al. [18] have worked towards enhancing the tracking performance of MPPT using simulation-based study. A case study of reluctance motor was considered for investigating the MPPT performance in water pumping motor by Koreboina et al. [19]. The study has emphasized on lower peaks of phases with highly controlled noise level. Kumar et al. [20], [21] have used machine learning approach for developing controller with efficient MPPT as well as the authors have also worked on extraction of power efficiently. Lasheen et al. [22] have worked on incorporating adaptivity inobtaining MPPT using reference voltage system. Leicht et al. [23] have developed an optimized model for controlling MPPT with highest degree of efficiencyconsidering harvester design of vibration energy. Adoption of swam intelligence was seen in study of Liu et al. [24] for ensuring better stability on the MPPT outcomes. Study towards energy harvestor was also found to be adopted by Liu et al. [25] in order to obtain better value of MPPT followed by removal of any dependencies on capacitor storage. A Parameterized-based model was adopted in the work of Miao et al. [26] considering single step of determination of MPPT followed by using multiple parameter models. However, the system is highly recursive in its operation. Peng et al. [27] have presented another unique model of MPPT considering similar condition of partially shaded condition. Adoption of machine learning-based approach was also reported in the work of Reddy and Sudhakar [28] where neural network has been implemented for optimizing outcomes. A non-linear-based approach of computing MPPT was seen in the work of Taheri and Taheri [29] considering a model with two diodes. Study towards investigating effectiveness of step-sized based approaches of optimization was seen in the work of Tang et al. [30] as well as Thangavelu et al. [31]. The investigation was carried out considering performance of steady-state. Wang et al. [32] have enhances the mechanism of processing power in PV cell in order to obtain better controlling mechanism of MPPT. Apart from this, the study also emphasized on achieving better accuracy of it using differential processing of power technique. The sudy is done by Purwahyudi et al. [33] "self constructing neural network (SCNN)" technuqe employed to enhance the accuracy of the electrnical characteristics in to the solar PV cell model. Similarly Pradhan and Panda [34] this review study focused on real time experiment to examine the result of differents factors like irradiance, heat, and angle of tilt, soiling, darkness over the power outcome of the pv- 
module. By Mankour et al. [35] demonstarted modeling of a stand alone energy system which is focused over Photovoltaic energy techniques. The next section briefly discusses about problems identified as major research issues associated with MPPT in PV cells.

\subsection{The problem}

The significant research problems are as follows:

a. None of existing techniques are ever assessed for offering computationally efficiency from its performance analysis.

b. Existing approaches incorporates more number of external parameter in order to obtain better output of MPPT, which is expensive in real-life application design.

c. Usage of PV array and its simplified optimization technique is very few to find in existing system where the dependencies are more for iterative machine learning approaches.

d. Lesser extent of simplified mathematical modeling exists which reduces the scope of implementation of the cost effective model for reaching MPPT.

The statement of significant problem identified for proposed system is "Developing a cost effective computational model where a simplistic approach of enhancing the MPPT positions can be obtained with faster response time in PV-cells is quite challenging."

\subsection{Proposed solution}

The principle aim of the proposed system is to design and develop a very simple model of DC-DC converter using PV cell that can be used for assessing its MPPT. In order to evaluate the proposed aim, it is essential that all the components be numerically designed and is subjected to higher degree of flexibility in order to check the best performance of proposed system. Therefore, the proposed system adopts analytical research methodology that retains the capability of both empirical evaluation as well as mathematical modeling. The analytical scheme of the proposed system is showcased in Figure 1.

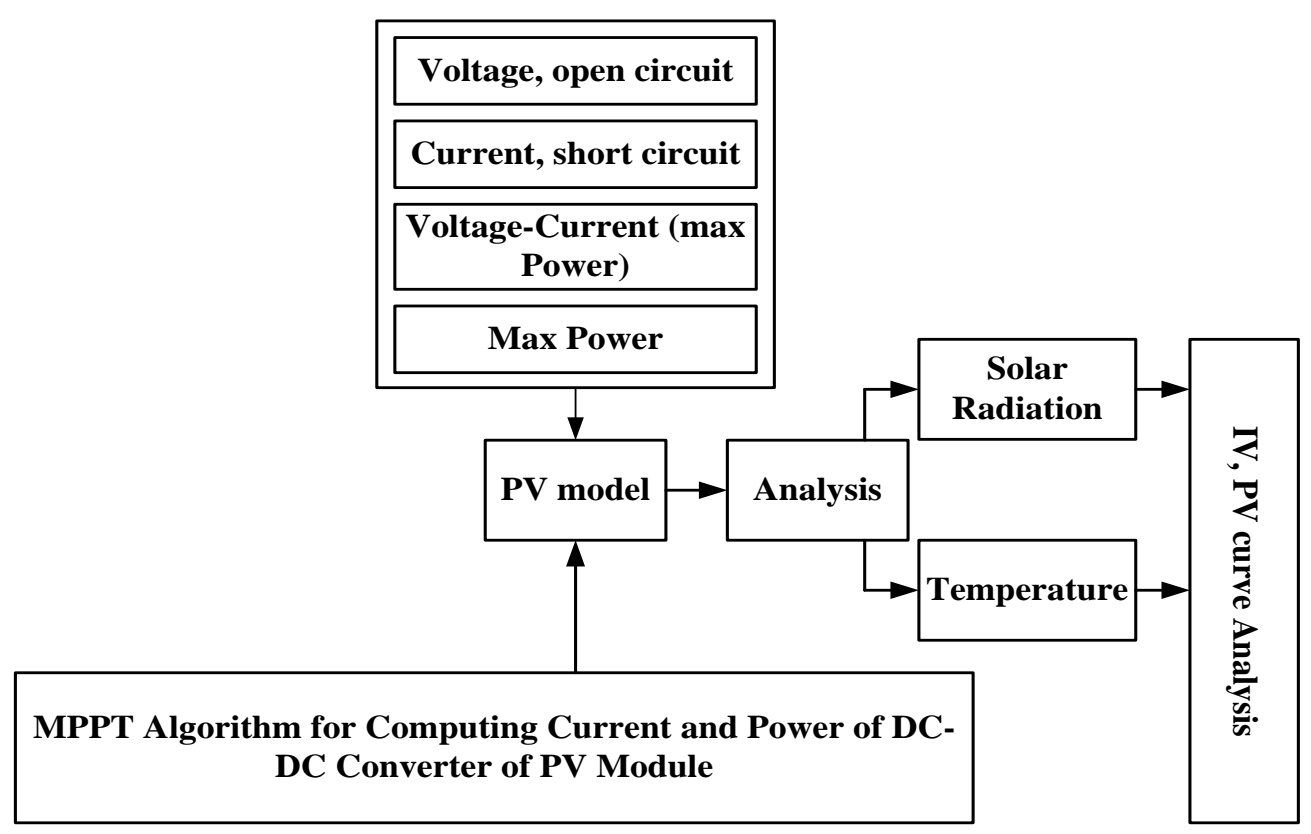

Figure 1. Analytical scheme of propsoed scheme

Figure 1 highlights the simplistic view of the proposed model that undertakes 4 different types of input i.e. voltage corresponding to open circuit, current corresponding to close circuit, both current and voltage corresponding to maximum power and maximum power of the PV cells. The proposed system also introduces an algorithm that assists in numerically as well as graphically exploring the MPPT where the analysis is carried out considering the test cases of both solar radiation and temperature. The final outcome of the proposed study is assessed with respect to the current-voltage and power-voltage curve. The study considersPV cell to be origination point of energy while a DC-DC controller is utilized for rectifying the identified fluctuation explored in both voltage and current charecteristics offered by given solar cells. 
The contribution of the above shown design is that it significantly assists ini obtaining the highest value of power as well as it insists the PV cell for working with an allocated voltage that is very much closer to highest value of the power for the purpose of drawing highest power.

\section{ALGORITHM IMPLEMENTATION}

The algorithm is introduced in order to better understand the flow of the proposed system with respect to its mathematical modeling. The core basis of the mathematical modeling is to offer importance to the enhancement of the current and voltage curve. Some of the essential parameters for the modeling are scale current, diode current, thermal voltage, and emission coefficient. The steps involved in proposed algorithm are as follows:

MPPT Algorithm for Computing Current and Power of DC-DC Converter of PV Module

Input: $\mathrm{n}$ (number of PV nodes)

Output: I (Current), P (Power)

Start

1) init $n$

2) For $\mathrm{i}=1: \mathrm{n}$

3) $\mathrm{I}_{\phi} \rightarrow \mathrm{I}_{\mathrm{P} 1} \cdot \beta$

4) compute resistive current $\operatorname{Ir}=\mathrm{f}(\mathrm{Is} /(\mathrm{B}-1))$

5) For $\mathrm{j}=1: \mathrm{m}$

6) $\tau \rightarrow \operatorname{size}(\theta)-[\mathrm{H} 1 / \mathrm{H} 2]$

7) End

8) Obtain I and P

End

The operation of the algorithm is as follows:-The algorithm considers different forms of inputs from the PV cell where the important parameter is $n$ that represents number of PV nodes (Line-1). It has to be understood that similar look will be constructed for considering either solar power as input or thermal coefficient as input. Therefore, the value of $n$ will corresponds to standard value of solar radiation i.e. one thousand watt per square meters as well as the algorithm will also consider the array voltage, which is basically an array with three specific information of arra voltage, cardinality of sun, and thermal coefficient. However, the proposed system fine-tunes it and develops a simple PV array considering three essential components as shown in Figure 2.

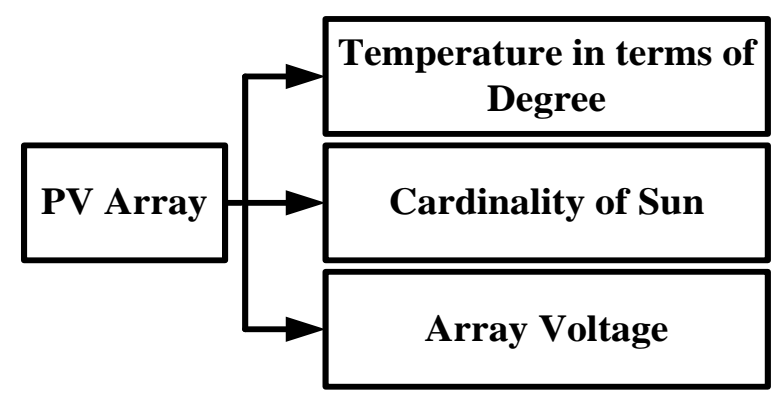

Figure 2. Formation of Array Current Matrix

The study also considers a parameter $C$ as specific value for specifying the cardinality of all the PV cells that are interconnected to each other in the form of series connection. Hence, the expression for voltage of open circuit at two different temperature scale can be empirically represented as,

$$
\mathrm{V}_{1} \rightarrow \mathrm{a}_{1} / \mathrm{C} \& \mathrm{~V}_{2} \rightarrow \mathrm{a}_{2} / \mathrm{C}
$$

The algorithm also considers two other essential parameters called as operational temperature $\mathrm{T}_{\mathrm{o}}$ and modeling temperature $\mathrm{T}_{\mathrm{m}}$ that is directly derived from standard temperature in form of degree. The proposed algorithm also considers involvement of the phase current $I_{\phi}$ that is mathematically computed (Line-3) considering two dependency factors i.e. $I_{P 1}$ and $\beta$. The first simulation parameter $I_{P 1}$ is called as phase current 
at temperature $\mathrm{T}_{1}$ and is computed as,

$$
\mathrm{I}_{\mathrm{P} 1} \rightarrow \mathrm{I}_{\alpha 1} \cdot \mathrm{S}_{\mathrm{em}}
$$

In the above expression, the dependable variables $I_{\alpha 1}$ and $S_{\mathrm{em}}$ represents corresponding current of circuit at specific value of $\alpha$ at temperature $T_{1}$ and emission of solar radiation respectively. Usage of $I_{p 1}$ is used as the first dependable variable for computing phases current $\mathrm{I}_{\phi}$ at Line-3. Similar mechanism is used for computing $I_{P 2}$ where the dependable parameters will be $I_{\alpha 2}$ and $S_{e m}$ respectively. The computation of $I_{P 2}$ is essential as without this the second parameter of computation of phase current i.e. $\beta$ cannot be calculated effectively. In order to compute $\beta$, the proposed system calculates $I_{P 2}$ as well as it reuses $I_{P 1}$ for evolving up with an expression for calculating optimized current for scaling. The expression for $\beta$ is given as,

$$
\beta \rightarrow\left[\frac{\Delta I_{s}}{I_{s 1}} \cdot \frac{1}{\Delta T}\right] .\left\{T_{o}-a b s\left(T_{1}\right)\right\}
$$

A closer look into the above expression will show that there are various dependable parameters e.g. $\Delta \mathrm{I}_{\mathrm{s}}, \mathrm{I}_{\mathrm{s}}, \Delta \mathrm{T}, \mathrm{T}_{\mathrm{o}}$, and $\mathrm{T}_{1}$. Basically, $\Delta \mathrm{I}_{\mathrm{s}}$ will mean an effective scaling coefficient obtained by difference of scaling coefficient corresponding to temperature $\mathrm{T}_{2}$ and $\mathrm{T}_{2}$ i.e. $\Delta \mathrm{I}_{\mathrm{s}}=\mathrm{I}_{\mathrm{s} 2}-\mathrm{I}_{\mathrm{s} 1}$. Similarly, $\Delta \mathrm{T}$ will mean an effective temperature score obtained difference of $T_{2}$ and $T_{1}$ i.e. $T_{2}-T_{1}$ (Line-3). The next part of the algorithm implementation would be to compute the resistive current Ir corresponding to both the temperature scale of $T_{1}$ and $T_{2}$. For this purpose, a specific function is constructed that is applicable for both the scaling coefficient of current factor at $T_{1}$ and $T_{2}$ respectively. Following is the expanded form of expressionfor $I_{r}$ (Line-4),

$$
I_{r}\left(T_{1}, T_{2}\right)=\frac{I_{s}\left(T_{1}, T_{2}\right)}{B-1}
$$

The parameter B in the denominator of expression (4) corresponds to exponential form of voltage of open circuit at temperature $T_{1}$ divided by scalar product of quality factor of diode and temperature $T_{1}$. The proposed system further computes effective current $\tau$ (Line-6) for different values of the voltage in order to check for maximum power point. This computation is carried out mathematically used Line-6 with an aid of different dependable parameters. A closer look into the expression will show effective current to be obtained by two different types of the parameters i.e. $\operatorname{size}(\theta)$ and $\left[\mathrm{H}_{1} / \mathrm{H}_{2}\right]$. Basically, the first parameter is a matrix with all elements zero of the dimension equivalent to size of a voltage with cardinality of the solar cells. The second parameter of the expression corresponds to following,

$$
\begin{aligned}
& \mathrm{H}_{1} \rightarrow \mathrm{I} \phi-\tau-\mathrm{I}_{\mathrm{r}}(\exp (\mathrm{E})) \\
& \mathrm{H}_{2} \rightarrow 1-\mathrm{I}_{\mathrm{r}}(\exp €) . \mu
\end{aligned}
$$

In the above expression, E will represents a value obtained by summing up voltage, current, and resistance while the entire sum is divided by an effective voltage. Similar, form of expression is used for computing H2. Hence, Line-6 assists in computing an effective current for the proposed PV cells. Finally, the system can easily compute the power of the PV cell just by multiplying voltage and current at PV cell (Line-6). This mechanism and its design principle is completely mathematical and a closer look into its design strategy will show some significant improvement with respect to existing mechanism. The first contribution of this algorithm is its simplicity for which reason it will never yield to any form of computational complexity. This process will directly contribute to offer faster response time by effectively generate the MPPT for the given DC-DC converter model e.g. PV cell. The second contribution of this algorithm is that it doesn't have any form of alteration towards the formation of any form of oscillator circuits with its streamlined connectivity with the capacitor, diode, and source of ower supply. With an aid of a battery, the instance of circuit obtaining the voltage than the charging operation is carried out by the capacitor residing the circuit using a resistor. This phenomenon doesn't require a massive form of engineering and is considerably simpler to achieve. The system than looks for the condition when the voltage applied to the capacitor is found to be more than than the thresholded voltage allocated to diode than in such circumstance then the diode design is initiated and plays the role of a switch for the given circuit. This is one of the essential reasons that lead the capacitor to discharge at a faster momentum using the proposed design principle. However, this process can also assists in deactivating the diode when the current transmitted through the designated diode is found to be less than thresholded current allocated in the diode. In such cases, 
the capacitor again charges up. This process actually assists in offering better identification of MPPT as normally such position of MMPT lies in closer proximity of the current-voltage curve. The proposed algorithm computes the essential voltage as well as an effective current considering the case of voltage corresponding to current factor associated with open as well as closed circuit too. However, with the consideration of thermal factor, the outcome of the power of the PV cell could be further accurately derived. The process also leads to the generation of the current and voltage curve that offers best way to analyze the study effectiveness. The outcome of this algorithm significantly assists in performing the entire necessary configuration to the array of the PV cell that indirectly helps in working much closer to the highest feasible condition of maximum power point. Finally, the algorithm measures the highest effective power (Line-8) for the given PV cell when it is completely allowed to be exposed to the standard solar emission. Also, a closer look into the algorithm design will show that proposed algorithm is absolutely not iterative by any means even it offers better outcomes which is very much essential to prove the computational efficiency of the proposed algorithm design. The next section discusses about the outcome obtained by implementing the discussed algorithm of proposed system for MPPT computation.

\section{RESULT ANALYSIS}

This section discusses about the outcomes obtained from the implementation of the proposed system. The scripting of the proposed logic was carried out in MATLAB considering voltage at open circuit condition as $20 \mathrm{~V}$, current at short circuit stage to be quivalent to $3.50 \mathrm{~A}$, voltage and current corresponding to maximum power to be $16 \mathrm{~V}$ and $3.5 \mathrm{~A}$, while the maximum power is considered to be $60 \mathrm{~W}$. The study considers band gap voltage to be $1.12 \mathrm{~V}$ and quality factor of the diode to be 1.2. All these are just standard test conditions that are frequently adopted by many researchers while all of these are flexible to be altered for assessing the MPPT of proposed system. The complete analysis of MPPT has been carried out considering both solar radiation and temperature factor.

Figure 3 and Figure 4 highlights the Current-Voltage curve and Power-Voltage curve, where the MPPT positions of 5 cardinalities of solar radiation has been testified. A normal look into the trend shows that current factor minimizes with the increase of voltage of PV cells in IV curve at $25^{\circ} \mathrm{C}$ (Figure 3 ) while power increases with increase in voltage factor until MPPT when it is found to be degraded after that. A promity comparison between both the graphical analysis will show the similar convergence point (which is in closer proximiry of $20 \mathrm{~V}$ of PV cell). The MPPT points are highlighted in Figure 4. Exactly, similar interpretation can be found for Figure 5 and Figure 6. However, the trends of both power and voltage are slightly different for both the two forms of analysis i.e. solar and temperature factor. The curve for both current and power for analyzing solar factor is quite distinct with respect to different cardinality of solar radiation. However, this is not the case with temperature factor where different cardinalities of temperature results in nearly similar value of both current as well as power will certain point and then start degrading distinctly. Hence, a very peculiar trend analysis is possible using proposed system.

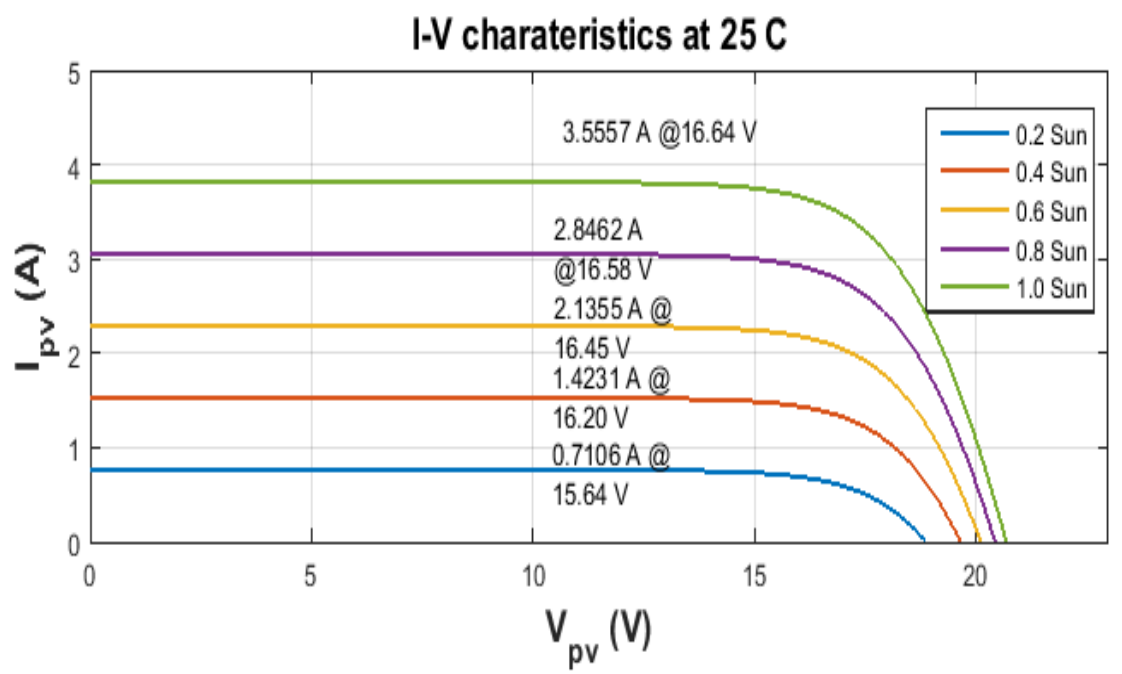

Figure 3. Analysis of IV Charecteristics at $25^{\circ} \mathrm{C}$ w.r.t. Solar factor 


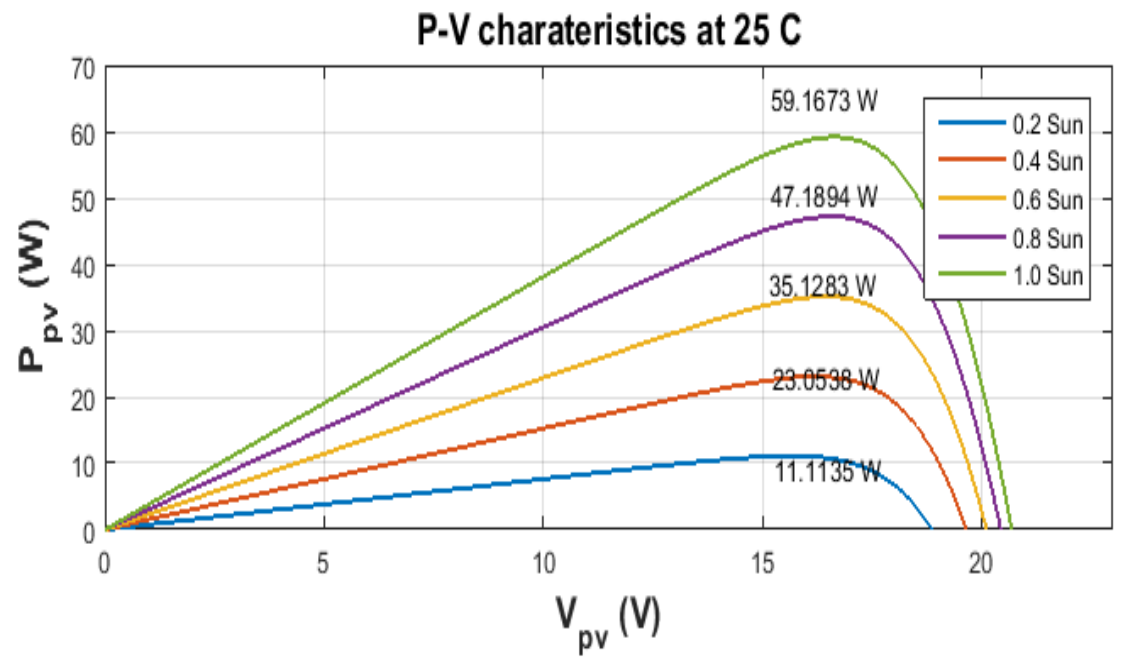

Figure 4. Analysis of PV Charecteristics at $25^{\circ} \mathrm{C}$ w.r.t. Solar factor

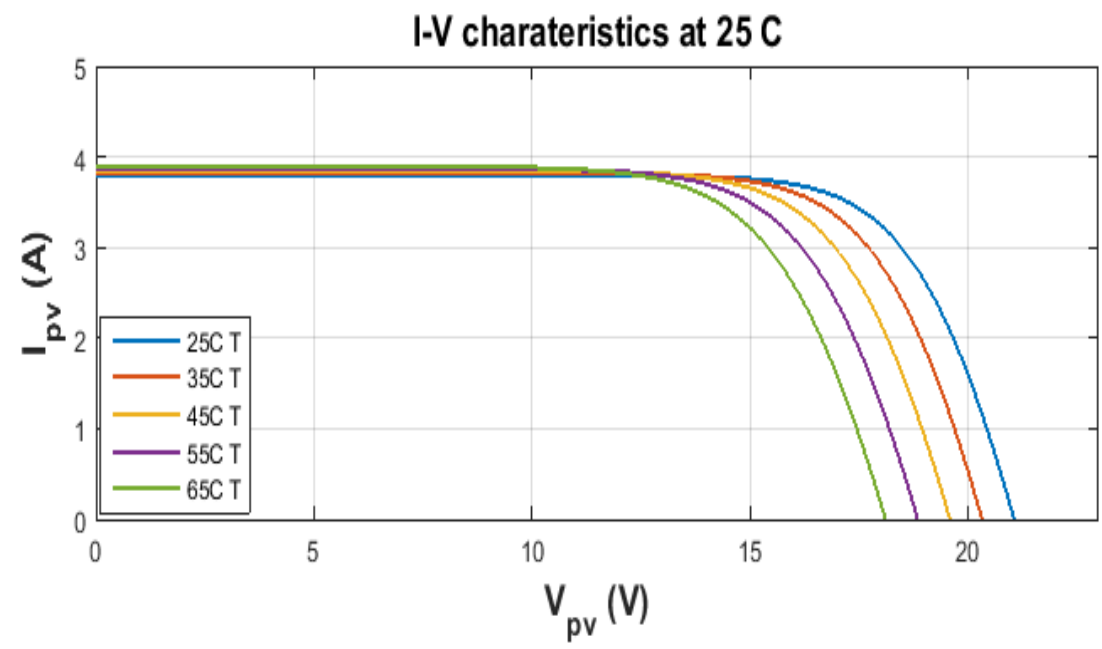

Figure 5. Analysis of IV Charecteristics at $25^{\circ} \mathrm{C}$ w.r.t. temperature factor

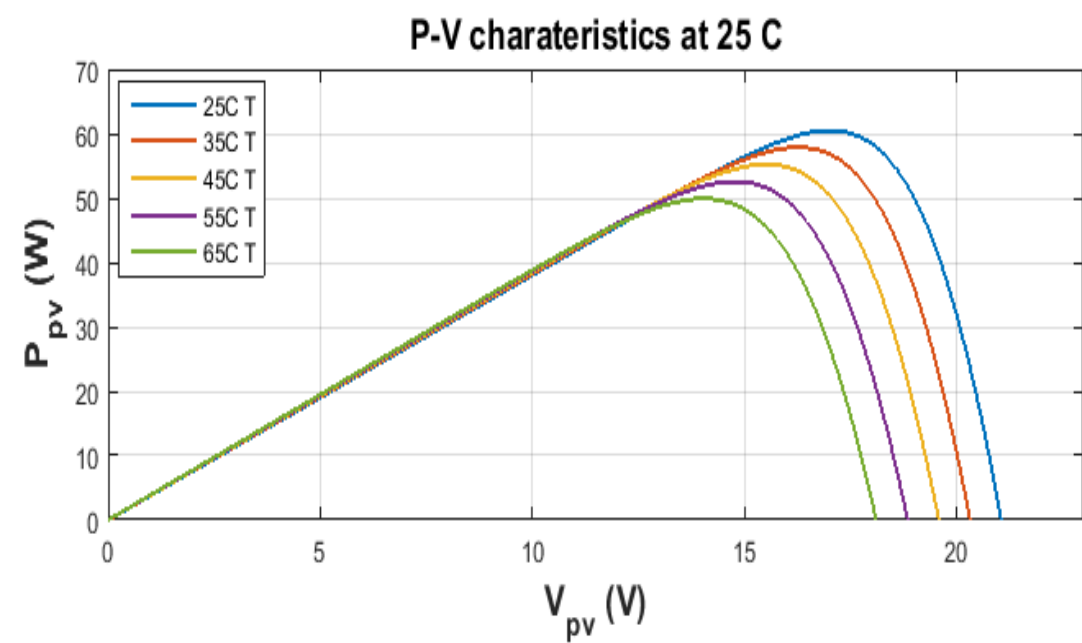

Figure 6. Analysis of PV Charecteristics at $25^{\circ} \mathrm{C}$ w.r.t. temperature factor 


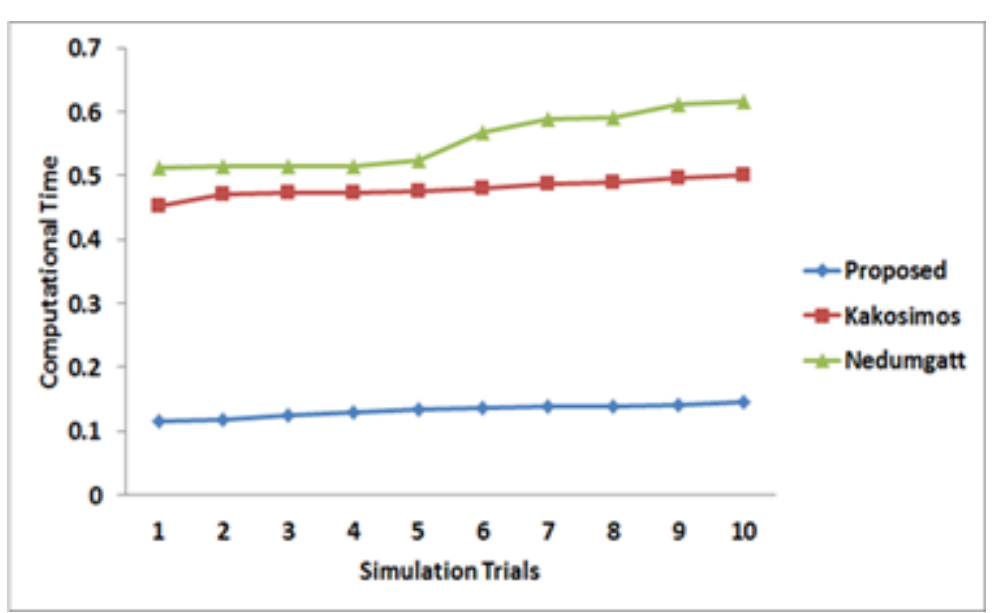

Figure 7. Comparative Analysis of Computational Time

The proposed system is also compared with the existing system in order to assess its computational performance with respect to processing time. Owing to simplistic design principle of proposed system, the computational time is found to be better with respect to existing system. The outcome shows that proposed system offers approximately $34.803 \%$ and $42.34 \%$ of improvement of computational performance time in comparison to PV models designed to assess MPPT by Kakosimos et al. [36] and Nedumgatt et al. [37]. Hence, proposed system offers cost effective computational model of MPPT evaluation in PV cells.

\section{CONCLUSION}

The proposed system introduces a simplified model for developing a PV cell in order to ensure better score of MPPT. The proposed system uses diode law with presence of diode with single junction, current, resistance (series), solar radiation, and temperature. The proposed sysem uses both solar and temperature parameter as the case study to evaluate the MPPT score. The study outcome is assessed with respect to current-voltage and power-voltage charecteristics. Considering a specific environment of DC-DC converter topology, the study outcome shows that an efficient and faster identification of MPPT. The study outcome was also found to offer faster computational processing time with respect to existing mechnanism of MPPT evaluation considering PV cells.

\section{REFERENCES}

[1] Md. Rabiul Islam, Faz Rahman, Wei Xu, Advances in Solar Photovoltaic Power Plants, Springer, 2016

[2] Weidong Xiao, Photovoltaic Power System: Modeling, Design, and Control, John Wiley \& Sons, 2017

[3] Angèle Reinders, Pierre Verlinden, Alexandre Freundlich, Photovoltaic Solar Energy: From Fundamentals to Applications, John Wiley \& Sons, 2017

[4] Suneel Deambi, Photovoltaic System Design: Procedures, Tools and Applications, CRC Press, 2016

[5] Carlos Algora, Ignacio Rey-Stolle, Handbook on Concentrator Photovoltaic Technology, John Wiley \& Sons, 2016

[6] Pankaj Kumar, Organic Solar Cells: Device Physics, Processing, Degradation, and Prevention, CRC Press, 2016

[7] Muhammad H. Rashid, Power Electronics Handbook, Butterworth-Heinemann, 2017

[8] B. G. Devi and M. Mahesh, "A brief survey on different multilevel inverter topologies for grid-tied solar photo voltaic system," 2017 IEEE International Conference on Smart Energy Grid Engineering (SEGE), Oshawa, ON, 2017, pp. 51-55.

[9] V. R. Vanajaa and C. Kathirvel, "DC-DC converter topology with maximum power point tracking strategies for renewable energy systems - A survey," 2017 Innovations in Power and Advanced Computing Technologies (i-PACT), Vellore, 2017, pp. 1-5.

[10] A. Mamen and U. Supatti, "A survey of hybrid energy storage systems applied for intermittent renewable energy systems," 2017 14th International Conference on Electrical Engineering/Electronics, Computer, Telecommunications and Information Technology (ECTI-CON), Phuket, 2017, pp. 729-732.

[11] Soualmia and R. Chenni, "A survey of maximum peak power tracking techniques used in photovoltaic power systems," 2016 Future Technologies Conference (FTC), San Francisco, CA, 2016, pp. 430-443.

[12] Yoganandini A.P., Anitha G.S., "Insights of the Advancement in Maximum Power Point Tracking Techniques in PV Module," Communications on Applied Electronics, vol. 4, no. 3, January 2016. 
[13] J. Ahmed and Z. Salam, "An Accurate Method for MPPT to Detect the Partial Shading Occurrence in a PV System," in IEEE Transactions on Industrial Informatics, vol. 13, no. 5, pp. 2151-2161, Oct. 2017.

[14] M. Tofigh Azary, M. Sabahi, E. Babaei and F. Abbasi Aghdam Meinagh, "Modified Single-Phase Single-Stage GridTied Flying Inductor Inverter With MPPT and Suppressed Leakage Current," in IEEE Transactions on Industrial Electronics, vol. 65, no. 1, pp. 221-231, Jan. 2018.

[15] M. A. Morales Caporal, J. d. J. Rangel Magdaleno, I. Cruz Vega and R. Morales Caporal, "Improved gridphotovoltaic system based on variable-step MPPT, predictive control, and active/reactive control," in IEEE Latin America Transactions, vol. 15, no. 11, pp. 2064-2070, Nov. 2017.

[16] M. A. Ghasemi, A. Ramyar and H. Iman-Eini, "MPPT Method for PV Systems Under Partially Shaded Conditions by Approximating I-V Curve," in IEEE Transactions on Industrial Electronics, vol. 65, no. 5, pp. 3966-3975, May 2018.

[17] S. B. Jeyaprabha and A. I. Selvakumar, "Model-Based MPPT for Shaded and Mismatched Modules of Photovoltaic Farm," in IEEE Transactions on Sustainable Energy, vol. 8, no. 4, pp. 1763-1771, Oct. 2017.

[18] R. Jiang, Y. Han and S. Zhang, "Wide-range, high-precision and low-complexity MPPT circuit based on perturb and observe algorithm," in Electronics Letters, vol. 53, no. 16, pp. 1141-1142, 2017.

[19] V. B. Koreboina, B. L. Narasimharaju and D. M. Vinod Kumar, "Performance investigation of simplified PWM MPPT approach for direct PV-fed switched reluctance motor in water pumping system," in IET Electric Power Applications, vol. 11, no. 9, pp. 1645-1655, 2017.

[20] K. Kumar, N. Ramesh Babu and K. R. Prabhu, "Design and Analysis of RBFN-Based Single MPPT Controller for Hybrid Solar and Wind Energy System," in IEEE Access, vol. 5, pp. 15308-15317, 2017.

[21] N. Kumar, I. Hussain, B. Singh and B. K. Panigrahi, "Single sensor based MPPT for partially shaded solar photovoltaic by using human psychology optimisation algorithm," in IET Generation, Transmission \& Distribution, vol. 11, no. 10, pp. 2562-2574, 2017.

[22] M. Lasheen, A. K. Abdel Rahman, M. Abdel-Salam and S. Ookawara, "Adaptive reference voltage-based MPPT technique for PV applications," in IET Renewable Power Generation, vol. 11, no. 5, pp. 715-722, 2017.

[23] J. Leicht and Y. Manoli, “A 2.6 \$mu text $\{\mathrm{W}\}$ \$ -1.2 mW Autonomous Electromagnetic Vibration Energy Harvester Interface IC with Conduction-Angle-Controlled MPPT and up to 95\% Efficiency," in IEEE Journal of Solid-State Circuits, vol. 52, no. 9, pp. 2448-2462, Sept. 2017.

[24] J. Liu, J. Li, J. Wu and W. Zhou, "Global MPPT algorithm with coordinated control of PSO and INC for rooftop PV array," in The Journal of Engineering, vol. 2017, no. 13, pp. 778-782, 2017.

[25] X. Liu, K. Ravichandran and E. Sánchez-Sinencio, "A Switched Capacitor Energy Harvester Based on a SingleCycle Criterion for MPPT to Eliminate Storage Capacitor," in IEEE Transactions on Circuits and Systems I: Regular Papers, vol. 65, no. 2, pp. 793-803, Feb. 2018

[26] J. Miao, D. Xie and R. Fan, "One-step MPPT method based on five-parameter model of PV panel," in The Journal of Engineering, vol. 2017, no. 13, pp. 917-921, 2017.

[27] R. Peng, K. C. Ho and Y. H. Liu, "A Novel and Fast MPPT Method Suitable for Both Fast Changing and Partially Shaded Conditions," in IEEE Transactions on Industrial Electronics, vol. 65, no. 4, pp. 3240-3251, April 2018.

[28] K. Jyotheeswara Reddy and N. Sudhakar, "High Voltage Gain Interleaved Boost Converter With Neural Network Based MPPT Controller for Fuel Cell Based Electric Vehicle Applications,” in IEEE Access, vol. 6, pp. 3899-3908, 2018.

[29] H. Taheri and S. Taheri, "Two-Diode Model-Based Nonlinear MPPT Controller for PV Systems," in Canadian Journal of Electrical and Computer Engineering, vol. 40, no. 2, pp. 74-82, Spring 2017.

[30] L. Tang, W. Xu and C. Mu, "Analysis for step-size optimisation on MPPT algorithm for photovoltaic systems," in IET Power Electronics, vol. 10, no. 13, pp. 1647-1654, 10272017.

[31] A, Thangavelu, S. Vairakannu and D. Parvathyshankar, "Linear open circuit voltage-variable step-size-incremental conductance strategy-based hybrid MPPT controller for remote power applications," in IET Power Electronics, vol. 10, no. 11, pp. 1363-1376, 2017.

[32] F. Wang, T. Zhu, F. Zhuo and H. Yi, “An Improved Submodule Differential Power Processing-Based PV System With Flexible Multi-MPPT Control," in IEEE Journal of Emerging and Selected Topics in Power Electronics, vol. 6, no. 1, pp. 94-102, March 2018.

[33] Purwahyudi, Bambang, Kuspijani Kuspijani, and Ahmadi Ahmadi, "SCNN Based Electrical Characteristics of Solar Photovoltaic Cell Model," International Journal of Electrical and Computer Engineering (IJECE), vol. 7, no. 6, pp. 3198-3206, 2017.

[34] Pradhan, Arjyadhara, and Bhagbat Panda, "Experimental Analysis of Factors Affecting the Power Output of the PV Module," International Journal of Electrical and Computer Engineering (IJECE), vol. 7, no. 6, pp. 3190-3197, 2017.

[35] Mankour, Salah Eddine, Ahmed Wahid Belarbi, and Mohammed Tarik Benmessaoud, "Modeling and Simulation of a Photovoltaic Field for $13 \mathrm{~kW}$," International Journal of Electrical and Computer Engineering (IJECE), vol. 7, no. 6, pp. 3271-3281, 2017.

[36] P. E. Kakosimos, A. G. Kladas and S. N. Manias, "Fast Photovoltaic-System Voltage- or Current-Oriented MPPT Employing a Predictive Digital Current-Controlled Converter," in IEEE Transactions on Industrial Electronics, vol. 60, no. 12, pp. 5673-5685, Dec. 2013.

[37] J. J. Nedumgatt, K. B. Jayakrishnan, S. Umashankar, D. Vijayakumar and D. P. Kothari, "Perturb and observe MPPT algorithm for solar PV systems-modeling and simulation," 2011 Annual IEEE India Conference, Hyderabad, 2011, pp. 1-6. 


\section{BIOGRAPHIES OF AUTHORS}
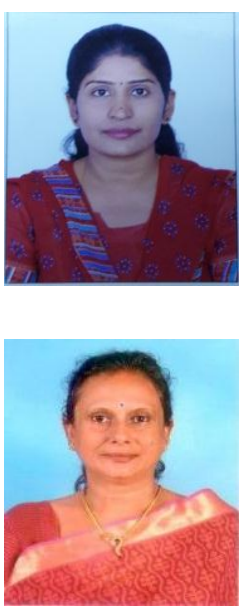

Yoganandini A. P., She has studied BE in Electrical \& Electronics Engineering from STJT, Karnataka university, Dharwad. M.Tech in computer applications in industrial drives from M. S. Ramaiah Institute of Technology, Bangalore from Visveswaraiah Technological university, Belgaum, Karnataka, India. Pursing PhD in area of Photovoltaic module. Published eight papers in International journals. Five papers in national conferences Attended international conference conducted at Dubai, UAE, got best paper award in year 2015 March. Currently working as an Assistant Professor in Sambharam Institute of Technology, Bangalore, Karnataka, India. Having 12 years of teaching experience.

Dr. Anitha She has studied BE in electrical \& Electrical engineering and M.Tech in power system Engineering from UVCE, Karnataka, India, PhD in Renewable energy source from Avinasamlingum University, koyamattur, Tamilnau, India Published Fifteen international Journals and Ten national journals and Attended Ten international conference. Having 34 years of teaching experience, currently working as an Associate Professor in Electrical \& Electronics Department R.V college of Engineering, Bangalore, Karnataka, India. 